\title{
A Homogeneous Dataset for Rainfall Trend Analysis in the Calabria Region (Southern Italy)
}

\author{
Tommaso Caloiero ${ }^{1, *(\mathbb{D})}$, Eugenio Filice ${ }^{2}$, Roberto Coscarelli ${ }^{3}\left[\right.$ ib and Gaetano Pellicone ${ }^{1(\mathbb{D}}$ \\ 1 National Research Council-Institute for Agricultural and Forest Systems in Mediterranean (CNR-ISAFOM), \\ 87036 Rende, Italy; gpellicone@gmail.com \\ 2 Multi-Risk Functional Center, Regional Agency for Environmental Protection of Calabria, \\ 88100 Catanzaro, Italy; e.filice@arpacal.it \\ 3 National Research Council-Research Institute for Geo-Hydrological Protection (CNR-IRPI), \\ 87036 Rende, Italy; roberto.coscarelli@irpi.cnr.it \\ * Correspondence: tommaso.caloiero@isafom.cnr.it; Tel.: +39-0984-841-464
}

Received: 15 July 2020; Accepted: 7 September 2020; Published: 11 September 2020

check for updates

\begin{abstract}
In order to investigate the tendency in rainfall amount in Calabria (southern Italy), in this work, monthly rainfall series were first tested for homogeneity and then a trend analysis was performed. In particular, a homogenization approach based on the Climatol method was applied to homogenize monthly climatological series. Then, the Mann-Kendall non-parametric test and the Theil-Sen estimator were applied to evaluate the presence of trends and their significance in the monthly, seasonal and annual rainfall series. Moreover, the trend slopes were further evaluated with a linear regression analysis. At the annual scale, results evidenced a decreasing trend mainly in the north-eastern part of the region. At the seasonal scale, a spatial distributed negative trend in winter, and a positive trend in summer, mainly localized in the north-western part of the region, were identified. Finally, on a monthly scale negative trends spreading across the region were detected in January and December, with an opposite behavior in July and especially in September, when almost the entire region presented a positive trend.
\end{abstract}

Keywords: rainfall; homogeneity; trend; Calabria

\section{Introduction}

Nowadays, climate change has received considerable attention, and several papers and technical studies have been conducted to detect its possible impacts all over the globe, such as the occurrence of drought events, severe storms and floods, extreme temperatures, and heat waves [1]. In this context, the detection of spatio-temporal rainfall variability becomes paramount for water resources management purpose [2]; also, trend analysis has been largely applied to identify the possible consequences of climate change in several hydrological temporal series around the world and especially, in major hotspots of climate change such as the Mediterranean Basin [3]. In fact, the Mediterranean Basin is located in a transition area, whose climate is affected by both the mild and rainy climate of central Europe and the arid climate of North Africa [1]. Results of the trend analysis performed in this area evidenced a widespread decrease in annual rainfall [4], albeit with some differences between the two sides of the basin [5]. In fact, while a decreasing rainfall trend, although irregular and highly variable across the decades, characterizes the western and central Mediterranean [6], the eastern Mediterranean presents different tendencies, with positive values in some areas $[7,8]$, and negative ones in others such as Israel $[9,10]$. For its position in the center of the western Mediterranean, and for its particular shape, extending over a wide latitude from north to south, Italy is especially important among the countries of the Mediterranean region. For this reason, in Italy, several rainfall trend analyses at the regional scale 
have been conducted. The majority of these studies analyzed rainfall trend at the annual timescale, evidencing a decrease in rainfall amount, especially in central [11,12] and in southern Italy [13]. At the same time, in southern Italy, different seasonal tendencies were identified, with a rainfall decrease in the winter-autumn months and an increasing rainfall amount in the summer period, such as in the studies performed in Campania [14], Basilicata [15], Sicily [16], Calabria [17], and Sardinia [18,19].

In order to perform reliable climate variability research, good quality long-term time series are required. In fact, several studies have demonstrated that climate change analyses are not imaginable without a clear understanding of the homogeneity of data. Indeed, the actual climate signal in original series can be hidden behind non-climatic factors, whose magnitude can be larger than the climate variation signals [20]. A climate record is considered homogeneous when its variations are caused only by changes in weather and climate. Unfortunately, time series are often affected by several non-climatic factors such as station relocations, modifications in the instrumentation and recalibrations, new formulae (e.g., used to evaluate mean temperature), changes in land use, variations in observation procedures, making these datasets misleading about the real climate changes [21]. Homogeneity testing and the correction of climatic time series for non-climatic variations are thus an essential part of any climate change analysis [22]. With this aim, in order to detect inhomogeneities in time series, many homogenization techniques have been developed in the past years, and numerous studies concerning the homogenization of long-term time series were performed all over the world [23]. Among the several methods to detect and remove inhomogeneities in a series, the most commonly used are based on the relative homogenization approach. This approach considers that neighboring stations are subject to almost the same climatic signal, and thus the differences between these stations can be useful to identify inhomogeneities [24]. In relative homogeneity testing, the time series of the station being tested (candidate station) is compared to the ones of multiple surrounding stations (reference stations) either in a pairwise fashion or to a single composite reference time series computed from multiple neighboring stations. Examples of homogeneous relative tests are the SNHT (standard normal homogeneity) [25], the Craddock test [26], the Caussinus-Mestre method [27] and the MASH (multiple analysis of series for homogenization) [28-30].

In this context, the present study will analyze data quality from the last 100 years for monthly rainfall in the Calabria region (southern Italy). First, a quality check was performed on the original database and inhomogeneities were identified and corrected. Then, a trend analysis was performed in order to identify possible trends at the monthly, seasonal and annual scales. Although this paper is not the first attempt to analyze the rainfall trend in Calabria, for the first time the trend analysis was performed on a homogeneous dataset with more than 100 years of observation.

\section{Study Area and Data}

The Calabria region is located at the toe of the Italian peninsula, at the center of the Mediterranean basin (between $37^{\circ} 54^{\prime}$ to $40^{\circ} 10^{\prime} \mathrm{N}$ and $15^{\circ} 36^{\prime}$ to $17^{\circ} 13^{\prime} \mathrm{E}$ ). The region has a surface of $15,080 \mathrm{~km}^{2}$ and presents a particular orography, being one of the most mountainous Italian regions, with $42 \%$ mountains, $49 \%$ hills and $9 \%$ flat areas (Figure 1). On average, its altitude is $597 \mathrm{~m}$ a.s.l. and its tallest relief is $2266 \mathrm{~m}$ a.s.l. Due to its position, the Köppen-Geiger classification [31] identifies the climate of the region as a warm temperate Mediterranean climate, thus presenting relatively mild winters (with rain) and dry, warm summers, with average temperatures higher than $22^{\circ} \mathrm{C}$. In particular, the Ionian side is influenced by currents from Africa while the Tyrrhenian side is subjected to western air currents; thus, they are affected by high temperatures with short and heavy rainfall and by milder temperatures and high precipitation, respectively. The inner areas of the region are, instead, characterized by cold winters with snow and fresh summers with occasional precipitation [32].

In Calabria, rainfall data have been collected since 1916 by the Multi-Risk Functional Center of the Regional Agency for Environment Protection. The data used in this study are a set of monthly rainfall series registered during the period of 1916-2018. In particular, at the end of 2018 the Calabria database consisted of data collected at more than 100 stations. All the rainfall series presenting more 
than $20 \%$ of lacking data in the observation period were discarded. As a result, data from 79 stations, with an average density of one station per $190 \mathrm{~km}^{2}$, were selected (Figure 1).

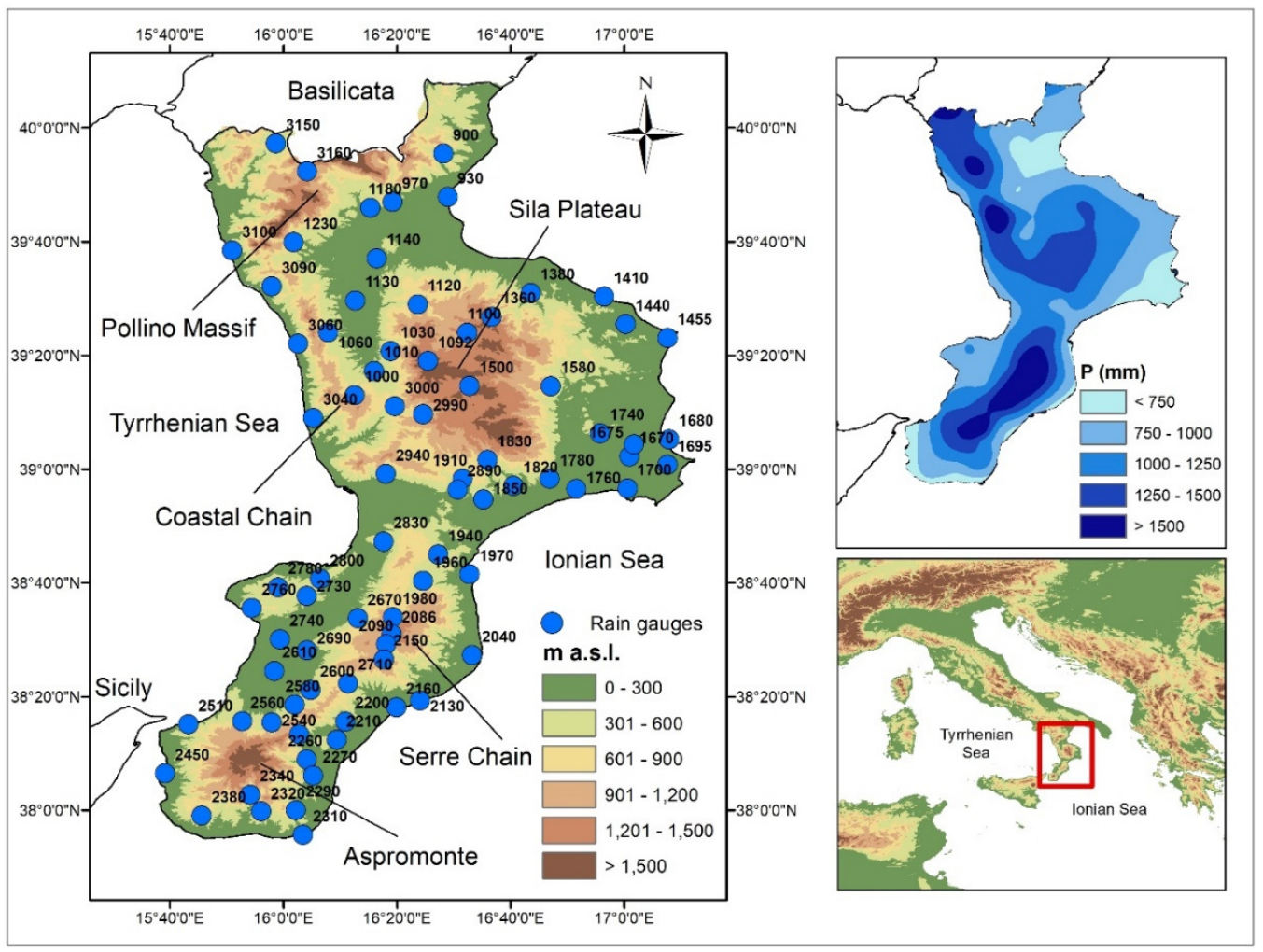

Figure 1. Localization of the rain gauges on a digital elevation model of the Calabria region and the spatial distribution of the mean annual rainfall.

\section{Methods}

\subsection{Homogenization Procedure}

Presently, the choice of the most suitable procedure among the several existing methods to detect and eliminate homogeneity problems in a series, depends on the characteristics of the dataset (e.g., metadata availability or station density) and on the examined region [22]. The homogenization approach used in this work is based on the Climatol method proposed by [33] and developed at the Spanish State Meteorological Agency (AEMET). Climatol was developed under the R programming language. The R package (https://CRAN.R-project.org/package=climatol) comprises several functions which allow quality control, homogenization and the infilling of the missing data in a dataset of a climatic variables. In particular, the homogenization approach developed in Climatol is based on the application of the well known standard normal homogeneity test (SNHT) proposed by Alexandersson [25]. SNHT is a parametric test considering reference stations to identify inhomogeneities in the time series of the candidate station. The choice of the reference stations is not only based on a proximity criterion, but also on a correlation criterion, because in highly correlated time series, the anomalies are essentially synchronous. In fact, due to the presence of a sharp orography (e.g., high mountains), the climate could vary a lot throughout the studied region, thus leading to the use of nearby but badly correlated stations to compute the reference series. The SNHT not only allows to identify changes (abrupt or linearly developing) between the candidate and the reference series, but also provides an estimate of the magnitude of the detected inhomogeneity that can be used to correct the series, and thus it is usually considered the most popular inhomogeneity test [34]. In order to identify and remove inhomogeneities, in Climatol an iterative procedure is applied. First, the maximum SNHT test values 
and their locations for every series are identified. Then, when the SNHT values of the series are greater than a fixed threshold, the series is divided at the point corresponding to the maximum SNHT and all the data before the break are moved to a new series, which is incorporated into the data pool with the same coordinates. After the first split of a series, the entire process is repeated dividing, at every cycle, only the series with the higher SNHT values, until no inhomogeneous series is found. Moreover, as the SNTH was originally developed to detect a single break-point in a series, the presence of more shifts in the mean could cover its results. In order to overcome this problem, in Climatol, the SNTH is first applied to stepped overlapping temporal windows, and then, it is applied to the complete series, where the test exhibits more power of detection [33].

\subsection{Trend Analysis}

After the homogenization procedure, in order to analyze the possible trends in rainfall series, two non-parametric tests for trend detection were used. In particular, the slopes of the trends were calculated by the Theil-Sen estimator [35] and the statistical significance was assessed with the Mann-Kendall (MK) non-parametric test [36,37]. The Theil-Sen estimator was selected because it is more powerful than linear regression methods in the trend slope evaluation in the presence of outliers in the series. In fact, the Theil-Sen estimator is not susceptible to the influence of extreme values.

Given $N$ pairs of data, the slope $\left(Q_{i}\right)$ can be calculated as follows:

$$
Q_{i}=\frac{x_{j}-x_{k}}{j-k} \text { for } i=1, \ldots, N,
$$

in which $x_{j}$ and $x_{k}$ are the data values at times $j$ and $k$ (with $j>k$ ), respectively.

If there is only one datum in each time period, then $N=n(n-1) / 2$, where $n$ is the number of time periods. If there are multiple observations in one or more time periods, then $N<n(n-1) / 2$, where $n$ is the total number of observations.

The $N$ values of $Q_{i}$ are ranked from smallest to largest and the median of the slope or Sen's slope estimator is computed as

$$
Q_{\text {med }}=\left\{\begin{array}{ll}
Q_{[(N+1) / 2]} & \text { if } N \text { is odd } \\
\frac{Q_{[N / 2]}+Q_{[(N+2) / 2]}}{2} & \text { if } N \text { is even }
\end{array},\right.
$$

The $Q_{\text {med }}$ sign reflects the data trend behavior, while its value indicates the steepness of the trend. For a series with dimension $n$, the $M K$ statistic is obtained as

$$
S=\sum_{i=1}^{n-1} \sum_{j=i+1}^{n} \operatorname{sgn}\left(x_{j}-x_{i}\right) ; \quad \text { with } \operatorname{sgn}\left(x_{j}-x_{i}\right)=\left\{\begin{array}{ccc}
1 & \text { if } & \left(x_{j}-x_{i}\right)>0 \\
0 & \text { if } & \left(x_{j}-x_{i}\right)=0 \\
-1 & \text { if } \quad\left(x_{j}-x_{i}\right)<0
\end{array},\right.
$$

where $x_{j}$ and $x_{i}$ are the data values at times $j$ and $i$, with $j>i$.

If $x_{i}$ are independent and randomly ordered, for $n>10$ the statistic $S$ follows a normal distribution with zero mean and variance given by

$$
\operatorname{Var}(S)=\left[n(n-1)(2 n+5)-\sum_{i=1}^{n} t_{i} i(i-1)(2 i+5)\right] / 18,
$$

with $\operatorname{Var}(S)$ variance of the $M K$ statistic and $t_{i}$ number of ties of extend $i$.

The standardized test statistic $Z_{M K}$ is computed as

$$
Z_{M K}=\left\{\begin{array}{cl}
\frac{S-1}{\sqrt{\operatorname{Var}(S)}} & \text { for } S>0 \\
0 & \text { for } S=0 \\
\frac{S+1}{\sqrt{\operatorname{Var}(S)}} & \text { for } S<0
\end{array}\right.
$$


Using a two-tailed test for a specified significance level $\alpha$, the null hypothesis is rejected if $\left|Z_{M K}\right|$ is greater than $Z_{1-\alpha / 2}$ and the trend can be considered significant.

Finally, a further analysis was conducted and the trend slopes were evaluated by means of a linear regression method.

\section{Results}

From the results of the homogenization procedure, 44 out of 79 monthly rainfall series resulted as homogeneous and 35 were homogenized. A total of 46 breaks were corrected in the whole dataset, with a maximum number of four breaks identified in two series and an average of 1.3 breaks per homogenized series.

After the homogenization of the monthly rainfall data, a trend analysis was performed. The results of the trend analysis applied to the monthly, seasonal and annual rainfall values, for a significance level equal to $95 \%$ are presented in Figure 2a, which shows the percentages of rain gauges evidencing positive or negative trends. In this figure, and in the following ones, seasons were divided considering December, January and February as winter, March, April and May as spring, June, July and August as summer and September, October and November as autumn.

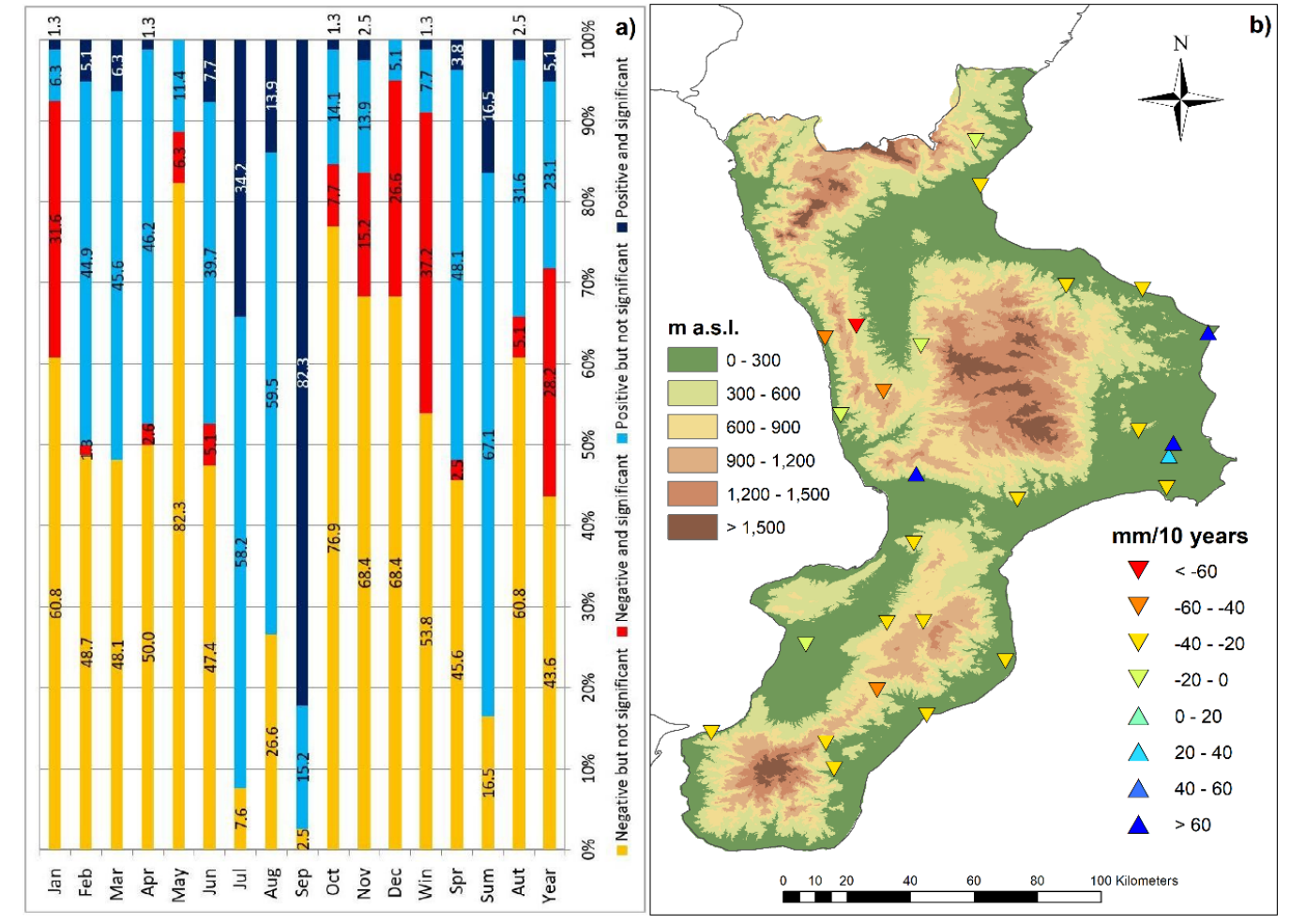

Figure 2. (a) The trends of the monthly, seasonal and annual rainfall values expressed as the percentage of rain gauges and $(\mathbf{b})$ the spatial distribution of rain gauges showing positive or negative annual rainfall trend.

As a result, at the annual scale, a prevalent rainfall decrease was detected. In fact, more than $28 \%$ of the annual rainfall series showed a negative trend, while significant positive trends were identified only in $5.1 \%$ of the series. This negative trend is spatially distributed throughout the entire study area (Figure $2 \mathrm{~b}$ and Table 1 ), with the highest magnitude detected in the area near the Coastal Chain, where the rainfall reduction reaches values higher than $60 \mathrm{~mm} / 10$ years.

Moreover, lower decreasing trends were identified in the eastern and in the southern side of the region, with magnitudes greater than $20 \mathrm{~mm} / 10$ years. Conversely, only four out of 79 stations showed a positive trend but with a magnitude higher than $60 \mathrm{~mm} / 10$ years (Figure $2 \mathrm{~b}$ and Table 1). 
At the seasonal scale, in winter, a marked negative trend was detected, with more than $37 \%$ of the rain gauges showing significant values. This trend behavior in winter was confirmed at the monthly scale, in particular in December and January, with $28.2 \%$ and $31.6 \%$ of the rain gauges showing a negative trend, respectively (Figure 2a). The spatial results of the trend analysis applied to the winter rainfall (Figure 3 and Table 1) evidenced a spatially distributed negative trend, similar to the annual one, with reductions higher than $30 \mathrm{~mm} / 10$ years in the Coastal Chain area.

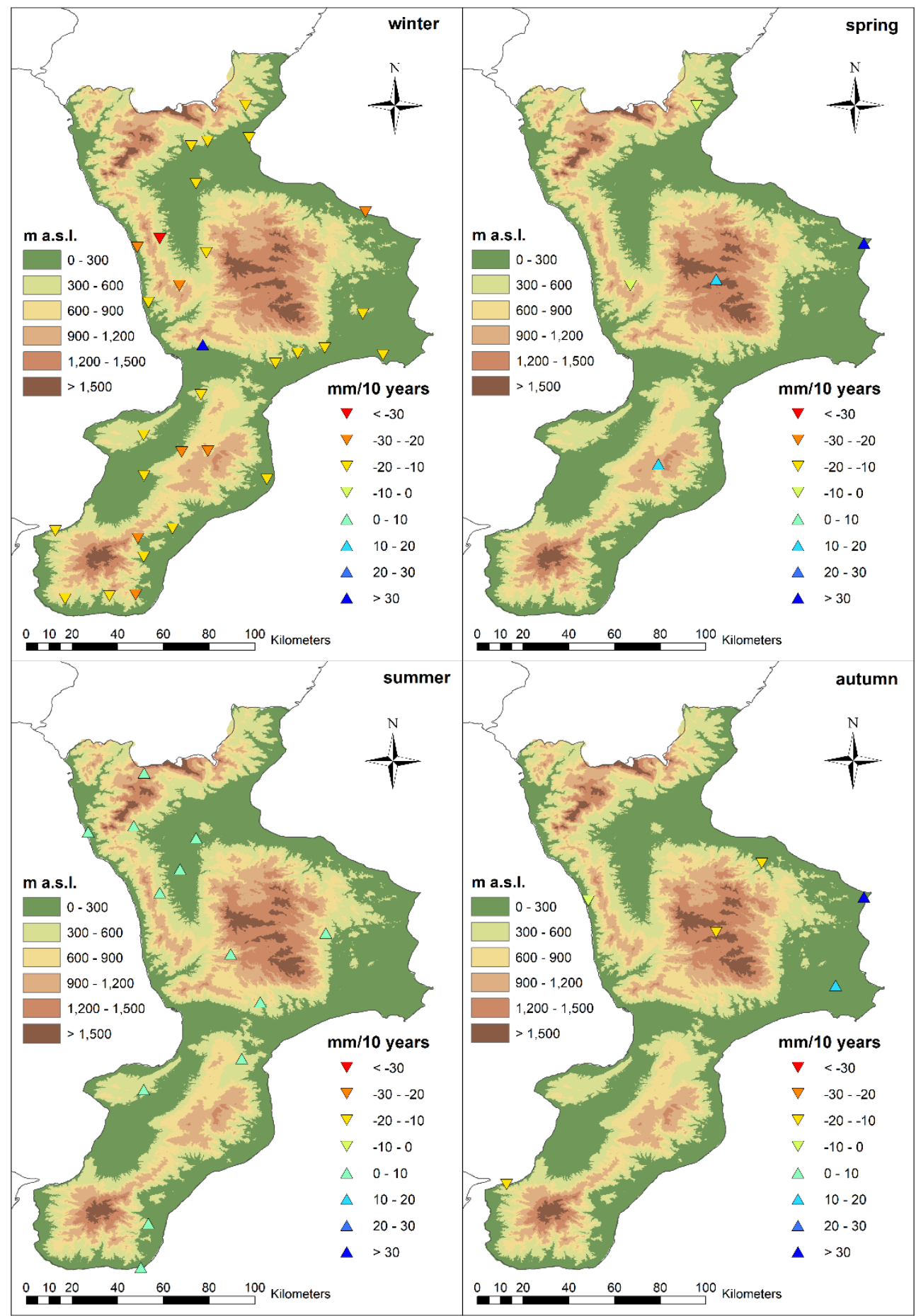

Figure 3. Spatial distribution of the rain gauges showing positive or negative seasonal rainfall trends. 
Table 1. Trend slopes ( $\mathrm{mm} / 10$ years) evaluated with the Theil-Sen estimator. Bold values identify significant trends.

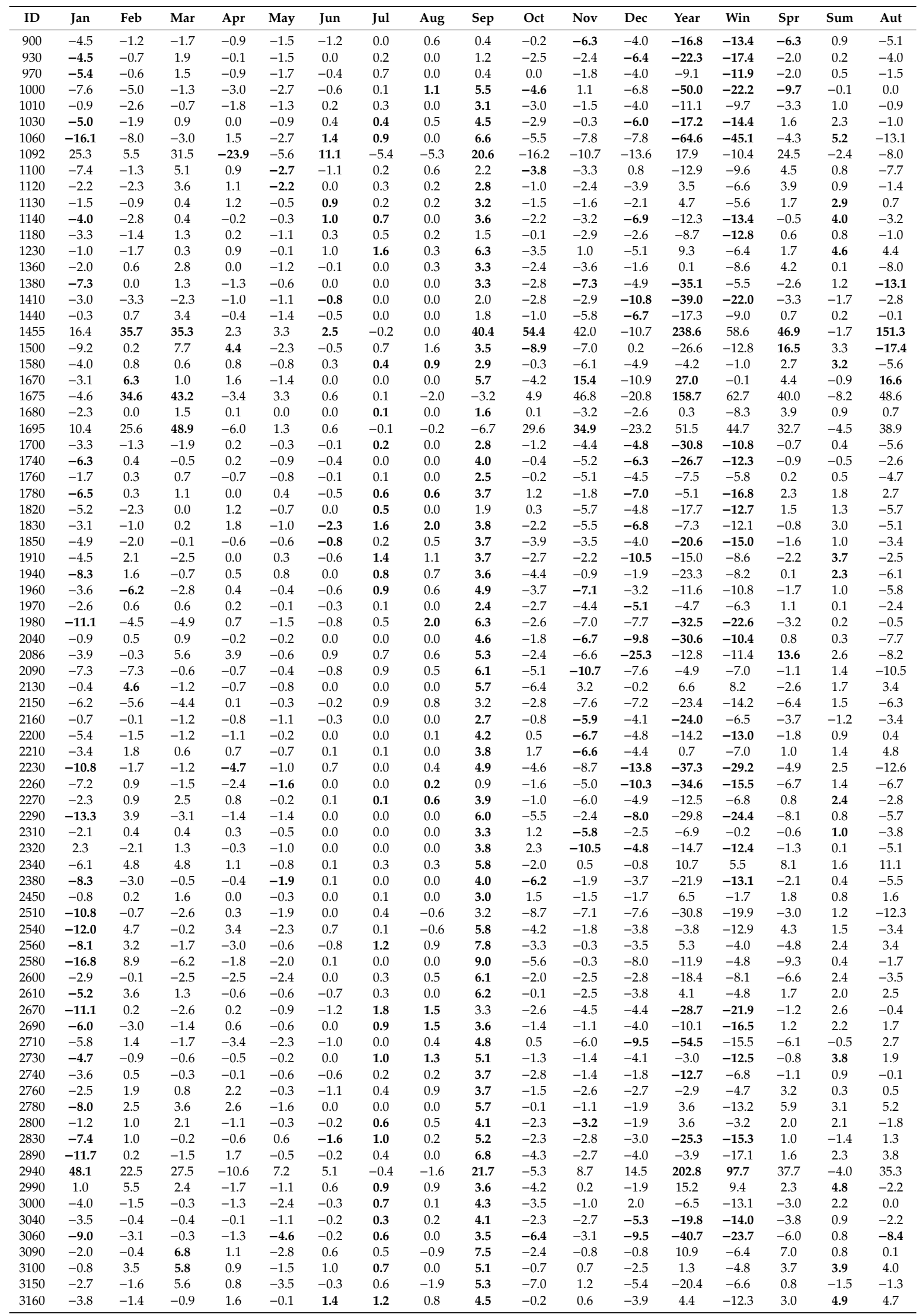


As opposed to the winter one, the summer precipitation showed a marked positive trend $(16.5 \%$ of the rain gauges) without any negative significant results. In particular, at the monthly scale, $7.7 \%, 34.2 \%$, and $13.9 \%$ of the rain gauges showed a positive trend in June, July, and August, respectively, and only $5.1 \%$ of the stations evidenced a negative trend in June (Figure 2a). A spatially distributed positive trend characterizes the results of the trend analysis applied to the summer rainfall, with slight increases between 0 and $10 \mathrm{~mm} / 10$ years in all the rain gauges (Figure 3 and Table 1). A similar spatial trend distribution was detected in July, with positive trends spreading across the region but with a magnitude between 0 and $10 \mathrm{~mm} / 10$ years (Figure 4 and Table 1). Additionally, in August, a maximum increasing magnitude between 0 and $10 \mathrm{~mm} / 10$ years was evaluated, but only in the central and southern parts of the region, while in the northern part no significant trends were detected (Figure 4 and Table 1).

In addition, negative trends with magnitudes greater than $20 \mathrm{~mm} / 10$ years were also identified in the southern part of the region across the Serre Chain and the Aspromonte. Moreover, lower decreasing trends were identified in the south-eastern side of the region. Only one rain gauge in the central part of the region showed a positive trend, but with a magnitude higher than $30 \mathrm{~mm} / 10$ years (Figure 3 and Table 1). On a monthly basis, in January, the highest negative trends were identified in the Coastal Chain and especially, around the Serre Chain and the Aspromonte, with magnitudes between $-10 \mathrm{~mm} / 10$ years and $-20 \mathrm{~mm} / 10$ years (Figure 4 and Table 1 ). A similar spatial trend distribution was detected in December with less rain gauges showing negative trends than in January, but with a higher magnitude also greater than $20 \mathrm{~mm} / 10$ years (Figure 4 and Table 1 ). A totally different behavior characterizes the spatial trend distribution in February, with few rain gauges on the Tyrrhenian side of the region showing positive values with a magnitude higher than $20 \mathrm{~mm} / 10$ years (Figure 4 and Table 1).

Regarding the spring months, no clear tendency was detected. In fact, in April, $2.6 \%$ (1.3\%) of the rain gauges evidenced a negative (positive) trend, while in March and in May only positive and negative trends were detected, respectively ( $6.3 \%$ of the rain gauges for both months). As a result of this monthly behavior, in spring, $2.5 \%$ of the rain gauges showed a negative trend and $3.8 \%$ a positive one (Figure 2a). The low number of significant trends is clearly shown considering the spatial distribution of the results (Figures 3 and 4, and Table 1). In fact, in spring, only three rain gauges located in the Sila Plateau, in the Serre Chain and in the Ionian coast showed a positive trend, with magnitudes reaching values higher than $30 \mathrm{~mm} / 10$ years. On the contrary, only one station in the Coastal Chain evidenced a negative trend with a reduction evaluated in less than $10 \mathrm{~mm} / 10$ years (Figure 3 and Table 1 ). On a monthly basis, in March, the positive trends were detected on the Ionian coast and in the north-eastern side of the region with a magnitude higher than $30 \mathrm{~mm} / 10$ years and between $5 \mathrm{~mm} / 10$ years and $10 \mathrm{~mm} / 10$ years, respectively (Figure 4 and Table 1 ). In contrast, in May, only reductions between 0 and $5 \mathrm{~mm} / 10$ years were evidenced (Figure 4 and Table 1 ).

Finally, in the autumn months, a very marked positive trend was observed in September $(82.3 \%$ of the rain gauges) while an opposite behavior was detected in October and in November with $7.7 \%$ and $15.2 \%$ of the rain gauges showing a negative trend, respectively. As a consequence of the monthly trends, in autumn, $5.1 \%$ of the rain gauges showed a negative trend while only $2.5 \%$ evidenced a positive one (Figure 2a). The first was detected in the central and western parts of the region (maximum magnitude between $-10 \mathrm{~mm} / 10$ years and $-20 \mathrm{~mm} / 10$ years) and the latter identified on the Ionian coast, also reaching values higher than $30 \mathrm{~mm} / 10$ years (Figure 3 and Table 1). The difference between September and the other autumn months is evident considering the spatial distribution of the trend on a monthly basis. In fact, in September, almost the entire region showed positive values with different magnitude values (Figure 4 and Table 1). On the other hand, in November, the spatial distribution of the results evidenced mixed positive and negative trends in the southeastern side of the region (Figure 4 and Table 1). In October, a prevalent negative trend was detected in the western side of the region, with rainfall reductions between $5 \mathrm{~mm} / 10$ years and $10 \mathrm{~mm} / 10$ years, while a positive trend was identified on the Ionian side, with a magnitude higher than $30 \mathrm{~mm} / 10$ years. 


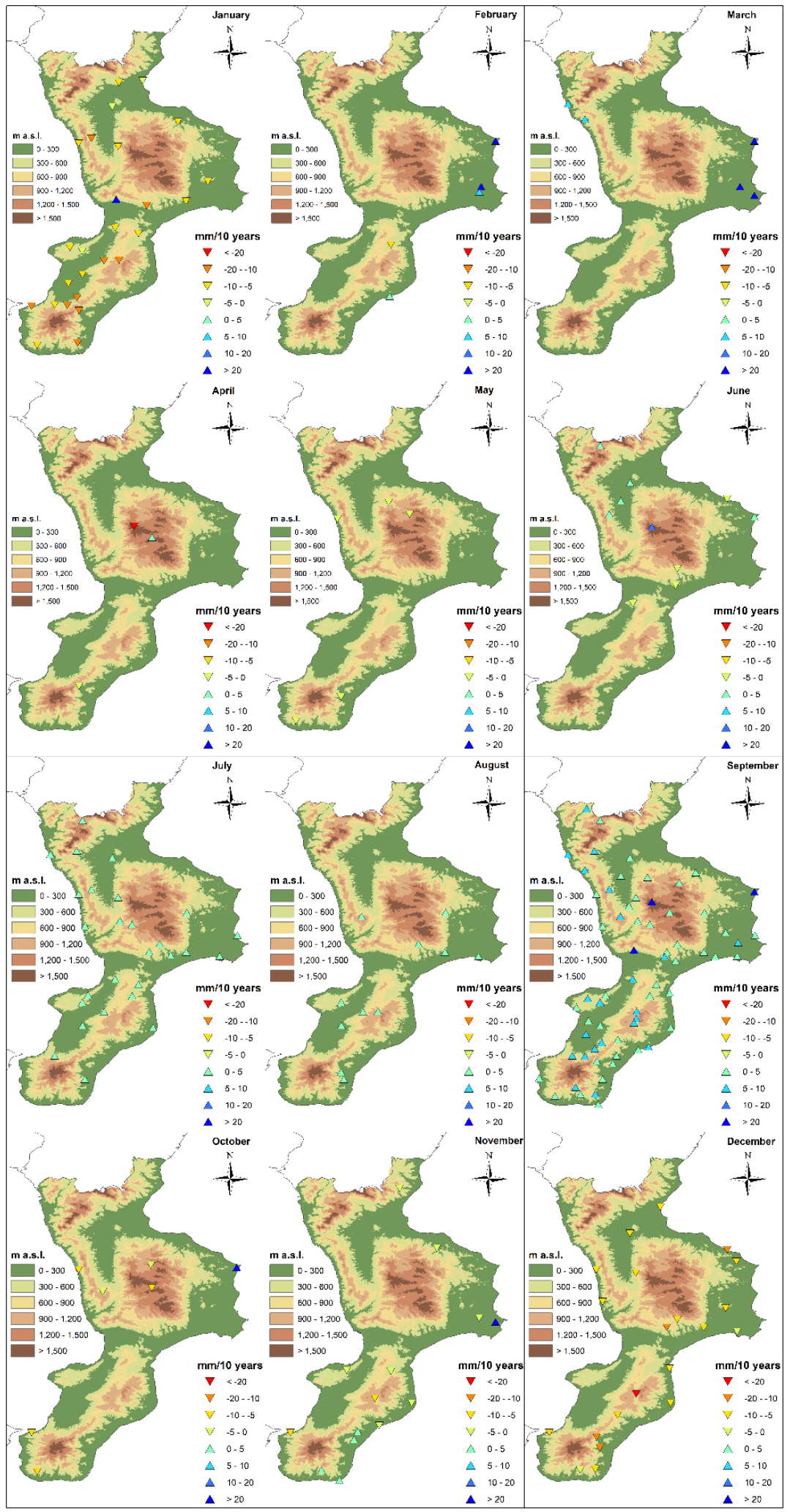

Figure 4. Spatial distribution of the rain gauges showing positive or negative monthly rainfall trends.

In order to further confirm the trend magnitude, the trend analysis was also performed by means of linear regression (Table 2). Indeed, the results of this analysis reflect the ones obtained with the previous tests (Table 1). 
Table 2. Trend slopes ( $\mathrm{mm} / 10$ years) evaluated with the linear regression. Bold values identify significant trends.

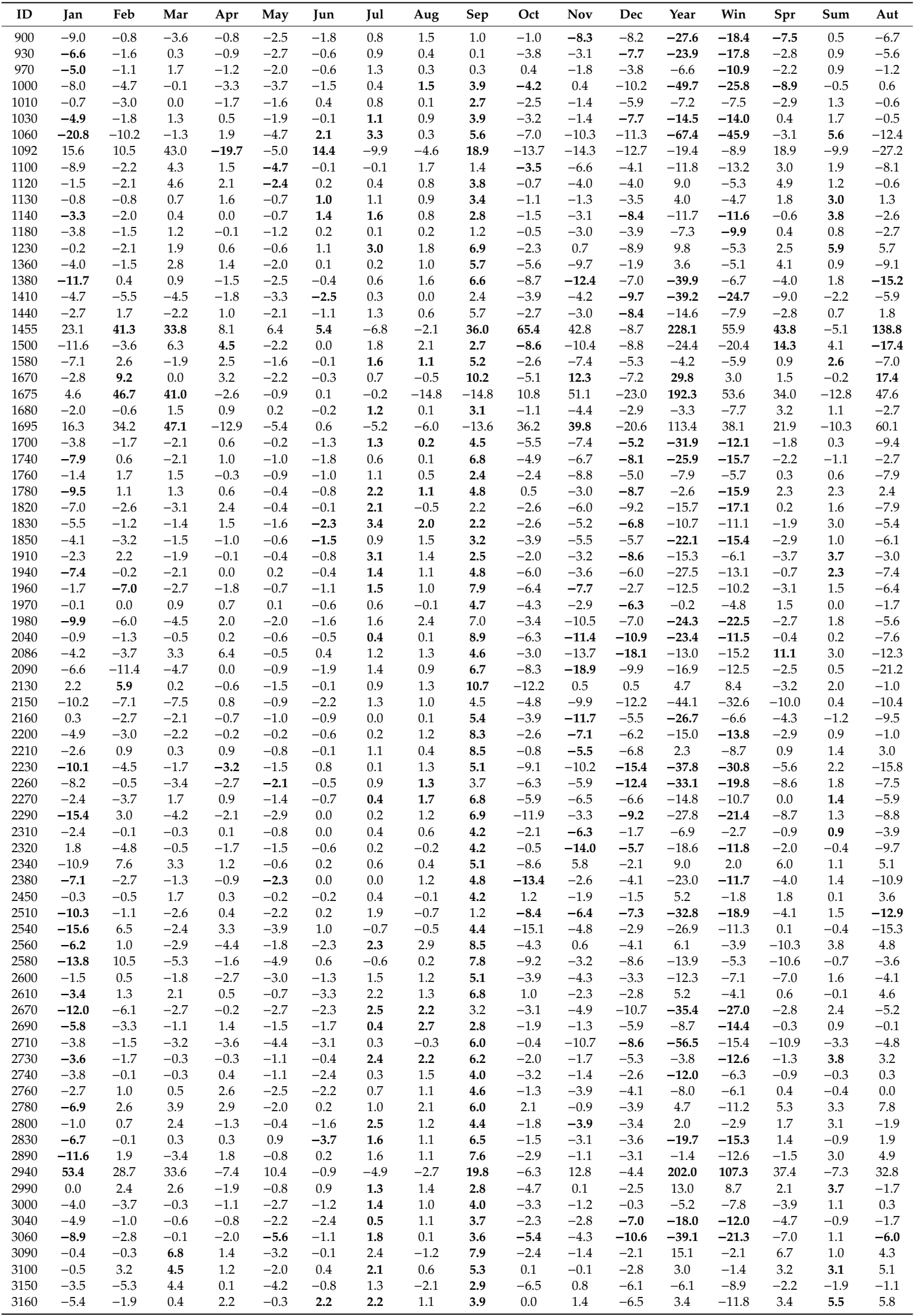




\section{Conclusions and Discussion}

Long-term observations of meteorological variables are paramount for monitoring ongoing climate change, and thus contrast their impacts on human and natural systems. In this context, there has recently been growing agreement in the scientific community about the fact that, in order to use meteorological time series for climate analyses, a clear knowledge of data homogeneity is required. In fact, scientists have become conscious of the fact that the real climate signal in a series of meteorological data can be hidden behind non-climatic noises caused by several factors, such as station relocation, changes in instruments, changes in observation times, observers, algorithms for the calculation of means, etc. The aim of this paper was to create a reliable rainfall database for the analysis of the climate trend in the Calabria region (southern Italy), where data collection started at the beginning of the past century, and where, therefore, climatological series longer than 100 years are available. With this aim, monthly rainfall series were first tested for homogeneity by applying the well known standard normal homogeneity test. In particular, in this paper, the Climatol package provided under the $\mathrm{R}$ programming language was applied because this method, by performing an iterative procedure, allows us to automatically identify and remove inhomogeneities from the series. Moreover, although it is acknowledged that homogenization methods cannot provide the real adjustment for artificial discontinuities affecting a climate time series, the efficiency of Climatol has been documented in several papers, also when compared to several other methods [23,38]. Finally, as pointed out by Fioravanti et al. [38] the choice of automatic methods is required when there is a high number of weather stations and a lack of metadata documenting potential change points. The results of the homogenization procedures allowed us to detect that more than $50 \%$ of monthly rainfall series resulted as homogeneous. Nevertheless, 35 out of 79 series were homogenized by correcting a total of 46 breaks and an average of 1.3 breaks per homogenized series.

After the homogenization procedure, in order to analyze the possible trends in the rainfall series, the Theil-Sen estimator and the Mann-Kendall non-parametric test were applied. Results evidenced a decrease in the rainfall amount at the annual scale, given by a reduction detected in winter, i.e., the rainy season in the Calabria seasons. Conversely, an increase in rainfall was identified in spring and especially, in summer, thus confirming past studies performed in other Italian regions which evidenced an increasing rainfall trend in the dry season and an opposite tendency in the wet season $[6,14,17,39]$. These different rainfall behaviors are probably linked to the time variability of the circulation types pointed out by Maheras et al. [7], who found a general positive trend of anticyclonic circulation, normally associated with a lower-than-average probability of rainfall, and a negative trend of cyclonic types.

Author Contributions: Conceptualization, T.C. and G.P.; methodology, T.C.; software, G.P. and T.C.; formal analysis, G.P. and T.C.; validation: T.C. and R.C.; investigation, T.C.; data curation, T.C. and E.F.; writing-original draft preparation, T.C. and R.C.; writing-review and editing, T.C. and R.C.; visualization, T.C.; supervision, R.C. and E.F.; project administration, T.C. All authors have read and agreed to the published version of the manuscript.

Funding: This research was funded by the Italian National Project PRIN 2015-4WX5NA "'Reconciling precipitation with runoff: The role of understated measurement biases in the modelling of hydrological processes."

Acknowledgments: The Project INDECIS, part of ERA4CS, an ERA-NET initiated by JPI Climate, and funded by FORMAS (SE), DLR (DE), BMWFW (AT), IFD (DK), MINECO (ES), ANR (FR) with co-funding by the European Union (Grant 690462).

Conflicts of Interest: The authors declare no conflict of interest.

\section{References}

1. IPCC. Summary for Policymakers. In Fifth Assessment Report of the Intergovernmental Panel on Climate Change; Cambridge University Press: Cambridge, UK, 2013.

2. Elmeddahi, Y.; Mahmoudi, H.; Issaadi, A.; Goosen, M.F.A.; Ragab, R. Evaluating the effects of climate change and variability on water resources: A case study of the Cheliff basin in Algeria. Am. J. Eng. Appl. Sci. 2016, 9 , 835-845. [CrossRef] 
3. Caloiero, T.; Coscarelli, R.; Gaudio, R. Spatial and temporal variability of daily precipitation concentration in the Sardinia region (Italy). Int. J. Climatol. 2019, 39, 5006-5021. [CrossRef]

4. del Rio, S.; Herrero, L.; Fraile, R.; Penas, A.P. Spatial distribution of recent rainfall trends in Spain (1961-2006). Int. J. Climatol. 2011, 31, 656-667.

5. Caloiero, T.; Caloiero, P.; Frustaci, F. Long-term precipitation trend analysis in Europe and in the Mediterranean basin. Water Environ. J. 2018, 32, 433-445. [CrossRef]

6. Longobardi, A.; Villani, P. Trend analysis of annual and seasonal rainfall time series in the Mediterranean area. Int. J. Climatol. 2010, 30, 1538-1546. [CrossRef]

7. Maheras, P.; Tolika, K.; Anagnostopoulou, C.; Vafiadis, M.; Patrikas, I.; Flocas, H. On the relationships between circulation types and changes in rainfall variability in Greece. Int. J. Climatol. 2001, 24, 1695-1712. [CrossRef]

8. Altin, T.B.; Barak, B. Changes and trends in total yearly precipitation of the Antalya District, Turkey. Procedia Soc. Behav. 2014, 120, 586-599. [CrossRef]

9. Shohami, D.; Dayan, U.; Morin, E. Warming and drying of the eastern Mediterranean: Additional evidence from trend analysis. J. Geophys. Res. 2011, 116, D22101. [CrossRef]

10. Ziv, B.; Saaroni, H.; Pargament, R.; Harpaz, T.; Alpert, P. Trends in rainfall regime over Israel, 1975-2010, and their relationship to large-scale variability. Reg. Environ. Chang. 2014, 14, 1751-1764. [CrossRef]

11. Scorzini, A.R.; Leopardi, M. Precipitation and temperature trends over central Italy (Abruzzo Region): 1951-2012. Theor. Appl. Climatol. 2019, 135, 959-977. [CrossRef]

12. Gentilucci, M.; Barbieri, M.; Lee, H.S.; Zardi, D. Analysis of Rainfall Trends and Extreme Precipitation in the Middle Adriatic Side, Marche Region (Central Italy). Water 2019, 11, 1948. [CrossRef]

13. Caloiero, T.; Coscarelli, R.; Ferrari, E.; Mancini, M. Trend detection of annual and seasonal rainfall in Calabria (Southern Italy). Int. J. Climatol. 2011, 31, 44-56. [CrossRef]

14. Diodato, N. Climatic fluctuations in southern Italy since 17th century: Reconstruction with precipitation records at Benevento. Clim. Chang. 2007, 80, 411-431. [CrossRef]

15. Piccarreta, M.; Capolongo, D.; Boenzi, F. Trend analysis of precipitation and drought in Basilicata from 1923 to 2000 within a Southern Italy context. Int. J. Climatol. 2004, 24, 907-922. [CrossRef]

16. Liuzzo, L.; Bono, E.; Sammartano, V.; Freni, G. Analysis of spatial and temporal rainfall trends in Sicily during the 1921-2012 period. Theor. Appl. Climatol. 2016, 126, 113-129. [CrossRef]

17. Coscarelli, R.; Gaudio, R.; Caloiero, T. Climatic trends: An investigation for a Calabrian basin (southern Italy). In The Basis of Civilization-Water Science? Rodda, J.C., Ubertini, L., Eds.; IAHS Publ: Wallingford, UK, 2004; pp. 255-266.

18. Montaldo, N.; Sarigu, A. Potential links between the North Atlantic Oscillation and decreasing precipitation and runoff on a Mediterranean area. J. Hydrol. 2017, 553, 419-437. [CrossRef]

19. Caloiero, T.; Coscarelli, R.; Gaudio, R.; Leonardo, G.P. Precipitation trend and concentration in the Sardinia region. Theor. Appl. Climatol. 2019, 137, 297-307. [CrossRef]

20. Della-Marta, P.M.; Collins, D.; Braganza, K. Updating Australia's high quality annual temperature dataset. Aust. Meteorol. Mag. 2004, 53, 75-93.

21. Peterson, T.C.; Easterling, D.R.; Karl, T.R.; Groisman, P.; Nicholls, N.; Plummer, N.; Torok, S.; Auer, I.; Boehm, R.; Gullett, D.; et al. Homogeneity adjustments of in situ atmospheric climate data: A review. Int. J. Climatol. 1998, 18, 1493-1517. [CrossRef]

22. Brunetti, M.; Caloiero, T.; Coscarelli, R.; Gullà, G.; Nanni, T.; Simolo, C. Precipitation variability and change in the Calabria region (Italy) from a high resolution daily dataset. Int. J. Climatol. 2012, 32, 57-73. [CrossRef]

23. Mamara, A.; Argiriou, A.A.; Anadranistakis, M. Homogenization of mean monthly temperature time series of Greece. Int. J. Climatol. 2013, 33, 2649-2666. [CrossRef]

24. Conrad, V.; Pollak, C. Methods in Climatology; Harvard University Press: Cambridge, MA, USA, 1950.

25. Alexandersson, H. A homogeneity test applied to precipitation data. Int. J. Climatol. 1986, 6, 661-675. [CrossRef]

26. Craddock, J.M. Methods of comparing annual rainfall records for climatic purposes. Weather 1979, 34, 332-346. [CrossRef]

27. Caussinus, H.; Mestre, O. New mathematical tools and methodologies for relative homogeneity testing. In Proceedings of the Seminar for Homogenization of Surface Climatological Data, Budapest, Hungary, 6-12 October 1996.

28. Szentimrey, T. Multiple Analysis of Series for homogenization (MASH). In Proceedings of the Second Seminar for Homogenization of Surface Climatological Data, Budapest, Hungary, 9-13 November 1998. 
29. Szentimrey, T. Manual of Homogenization Software MASHv3.02; Hungarian Meteorological Service: Budapest, Hungary, 2007.

30. Szentimrey, T. Development of MASH homogenization procedure for daily data. In Proceedings of the Fifth Seminar for Homogenization and Quality Control in Climatological Databases, Budapest, Hungary, 29 May-2 June 2006.

31. Beck, H.E.; Zimmermann, N.E.; McVicar, T.R.; Vergopolan, N.; Berg, A.; Wood, E.F. Present and future Köppen-Geiger climate classification maps at 1-km resolution. Sci. Data 2018, 5, 180214. [CrossRef] [PubMed]

32. Caloiero, T.; Callegari, G.; Cantasano, N.; Coletta, V.; Pellicone, G.; Veltri, A. Bioclimatic analysis in a region of southern Italy (Calabria). Plant Biosyst. 2016, 150, 1282-1295. [CrossRef]

33. Guijarro, J.A. User's Guide to Climatol. An R Contributed Package for Homogenization of Climatological Series. Report State Meteorological Agency; Balearic Islands Office: Palma de Mallorca, Spain, 2014. Available online: http://www.climatol.eu/climatol-guide.pdf (accessed on 23 June 2020).

34. Yazici, C.; Yozgatligil, C.; Batmaz, I. A simulation study on theperformances of homogeneity tests applied in meteorological studies. In Proceedings of the ICACM-International Conference on Applied and Computational Mathematics, Ankara, Turkey, 3-6 October 2012.

35. Sen, P.K. Estimates of the regression coefficient based on Kendall's tau. J. Am. Stat. Assoc. 1968, 63, 1379-1389. [CrossRef]

36. Mann, H.B. Nonparametric tests against trend. Econometrica 1945, 13, 245-259. [CrossRef]

37. Kendall, M.G. Rank Correlation Methods; Hafner Publishing Company: New York, NY, USA, 1962.

38. Fioravanti, G.; Piervitali, E.; Desiato, F. A new homogenized daily data set for temperature variability assessment in Italy. Int. J. Climatol. 2019, 39, 5635-5654. [CrossRef]

39. Piccarreta, M.; Pasini, A.; Capolongo, D.; Lazzari, M. Changes in daily precipitation extremes in the Mediterranean from 1951 to 2010: The Basilicata region, southern Italy. Int. J. Climatol. 2013, 33, 3229-3248. [CrossRef]

(C) 2020 by the authors. Licensee MDPI, Basel, Switzerland. This article is an open access article distributed under the terms and conditions of the Creative Commons Attribution (CC BY) license (http://creativecommons.org/licenses/by/4.0/). 